\title{
Pemenuhan Kebutuhan Personal Hygiene Lanjut Usia di UPT Pelayanan Sosial Lanjut Usia Jombang di Pare
}

\author{
Nugrahaeni Firdausi ${ }^{1}$, Maulana Rahmat Hidayatullah ${ }^{2 *}$ \\ ${ }^{1,2}$ STIkes Pamenang Pare Kediri, Indonesia \\ maulanarahmathidayatullah@gmail.com
}

\begin{abstract}
ABSTRAK
Peningkatan derajat kesehatan dan kesejahteraan penduduk pada saat ini akan berpengaruh pada peningkatan Usaha Harapan Hidup (UHH) di Indonesia yang semakin meningkat setiap tahunnya. Perubahan fisik, sosial, psikologis, dan moral spiritual yang terjadi pada lanjut usia dapat mengakibatkan timbulnya gangguan pemenuhan kebutuhan personal hygiene, sehingga dapat meningkatkan ketergantungan yang memerlukan bantuan orang lain. Lanjut usia di lingkungan panti werdha merupakan populasi yang rentan akan rendahnya perilaku personal hygiene. Kebutuhan personal hygiene merupakan hal yang sangat penting dan harus diperhatikan. Karena kebersihan akan mempengaruhi kesehatan, kenyamanan, keamanan, dan kesejahteraan lanjut usia. Tujuan dilakukan program ini adalah untuk bertujuan untuk membantu lanjut usia dalam pemenuhan kebutuhan personal hygiene. Metode yang digunakan dalam program ini adalah edukasi secara personal, motivasi, dan pemenuhan personal hygiene lanjut usia sesuai dengan tingkat ketergantungannya. Hasil dari program ini adalah edukasi, motivasi, dan pemenuhan personal hygiene lanjut usia erat hubungannya dalam pemenuhan kebutuhan dasar lanjut usia dan meningkatkan kesehatan bio, psiko, dan sosio-spiritual lanjut usia.
\end{abstract}

Kata Kunci: Lanjut usia, Personal hygiene, Kebutuhan dasar lansia

Received: December, 22, 2019

Revised: January 15, 2020

Accepted: February 27, 2020

This is an open-acces article distributed under the terms of the Creative Commons Attribution-ShareAlike 4.0 International License.

\section{PENDAHULUAN}

Peningkatan derajat kesehatan dan kesejahteraan penduduk pada saat ini akan berpengaruh pada peningkatan Usaha Harapan Hidup (UHH) di Indonesia (Maryani \& Kristiana, 2018; Nurfauziya, Prakosa, \& Kusuma, 2018; Syaifudin \& Nurhayati, 2018). Badan Pusat Statistik (BPS) melaporkan bahwa UHH pada tahun 2000 di Indonesia adalah 64,5 tahun (dengan persentase populasi lanjut usia adalah 7,18\%). Pada tahun 2010 terjadi peningkatan menjadi 69,43 (dengan persentase populasi lanjut usia adalah 7,56\%) dan pada tahun 2011 menjadi 69,65 tahun (dengan persentase populasi lanjut usia adalah 7,58\%). Jumlah lanjut usia di provinsi dengan persentase tiga tertinggi terdapat di Provinsi DI Yogyakarta (13,04\%), Jawa Timur (10,40\%), dan Jawa Tengah (10,34\%). Perubahan fisik, sosial, psikologis, dan moral spiritual yang terjadi pada lanjut usia dapat mengakibatkan timbulnya gangguan pemenuhan kebutuhan personal hygiene, sehingga dapat meningkatkan ketergantungan yang memerlukan bantuan orang lain (Lubis, 2016; 
Muhith \& Siyoto, 2016; Rohmah, 2019). Lanjut usia di lingkungan panti werdha merupakan populasi yang rentan akan rendahnya perilaku personal hygiene (Tiar, 2019; Usman, 2016; Yulaikhah, Arisdiani, \& Widiastuti, 2017). Penelitian Yulaikhah et al., (2017) menunjukkan, sebanyak 37,5\% lanjut usia menunjukkan pemenuhan kebutuhan personal hygiene masih kurang. Kebutuhan personal hygiene merupakan hal yang sangat penting dan harus diperhatikan. Karena kebersihan akan mempengaruhi kesehatan, kenyamanan, keamanan, dan kesejahteraan lanjut usia (Firmana, 2016; Tasti, 2018).

Dilatarbelakangi dari hal diatas program "Pemenuhan Kebutuhan Personal Hygiene lanjut usia" bertujuan untuk membantu lanjut usia dalam pemenuhan kebutuhan personal hygiene. Kebutuhan personal hygiene yang terpenuhi dengan baik diharapkan dapat meningkatkan kesehatan bio, psiko, dan sosio-spiritual lanjut usia.

Program pemenuhan kebutuhan personal hygiene lanjut usia akan dilaksankan di UPT Pelayanan Sosial Lanjut Usia Jombang di Pare, yang ditujukan untuk lanjut usia dengan personal hygiene yang kurang. Personal hygiene yang dilakukan mencakup perawatan kulit, perawatan kuku, perawatan mulut, perawatan mata, perawatan telinga, perawatan hidung, dan perawatan perineum. Jumlah lanjut usia di UPT Pelayanan Sosial Lanjut Usia Jombang di Pare pada bulan November 2019 adalah sebanyak 85 lanjut usia, yang menempati enam wisma, yaitu wisma mawar, anggrek, melati, dahlia, AWF A, dan AWF B.

Kelompok sasaran dinilai sesuai dengan tujuan program karena pemenuhan kebutuhan personal hygiene yang masih kurang pada lanjut usia, hal ini dibuktikan dengan sebanyak $50 \%$ lanjut usia membutuhkan bantuan dalam pemenuhan kebutuhan personal hygiene, yaitu perawatan kulit, perawatan kuku, perawatan gigi dan mulut, perawtaan rambut, perawatan mata, perawatan telinga, perawatan hidung, dan perawatan perineum.

Hal tersebut dipengaruhi oleh banyak faktor antara lain penurunan fungsi fisik, psikis, sosial, dan spiritual lanjut usia sehingga berpengaruh terhadap pemenuhan kebutuhan personal hygiene. Lanjut usia imobilisasi membutuhkan bantuan total dalam pemenuhan kebutuhan perawatan kulit, perawatan mulut, perawatan mata, perawatan telinga, perawatan hidung, dan perawatan perineum. Lanjut usia dengan penurunan fungsi organ persepsi sensoris membutuhkan bantuan dalam pemenuhan kebutuhan personal hygiene kebersihan kuku dan lingkungan.

Jumlah tenaga kesehatan di UPT Pelayanan Sosial Lanjut Usia Jombang di Pare juga terbatas, yaitu hanya dua orang perawat yang bertugas sesuai shift. Tenaga lainnya berasal dari tenaga non kesehatan yang bertugas sebagai penanggung jawab wisma, konsumsi, keamanan, dan administrasi. Satu orang penanggung jawab wisma masing-masing bertanggung jawab terhadap pemenuhan kebutuhan lanjut usia yang berjumlah kurang lebih 15-20 orang lanjut usia dalam satu wisma. Jumlah pegawai yang tidak seimbang dengan jumlah lanjut usia mengakibatkan pemenuhan kebutuhan personal hygiene lanjut usia yang kurang maksimal.

Program pemenuhan kebutuhan personal hygiene lanjut usia yang dilaksanakan diharapkan dapat meningkatkan kesehatan bio, psiko, dan sosio-spiritual lanjut usia.

\section{BAHAN DAN METODE}

Program pemenuhan kebutuhan personal hygiene lanjut usia dilakukan karena kedaan lanjut usia yang mengalami berbagai masalah :

1) Penurunan fungsi fisik, psikis, sosial, dan spiritual lanjut usia mempengaruhi pemenuhan kebutuhan personal hygiene lanjut usia.

2) Jumlah tenaga kesehatan yang kurang. 
3) Rasio pegawai penanggung jawab wisma adalah petugas non kesehatan dan tidak sebanding dengan jumlah lanjut usia.

4) Jumlah lanjut usia dengan tingkat ketergantungan minimal, sebagian, dan ketergantungan total banyak.

5) Tidak semua lanjut usia mandiri bisa membantu pemenuhan kebutuhan personal hygiene lanjut usia dengan ketergantungan minimal, sebagian, dan total

Program ini dilakukan selama empat minggu dengan cara memberikan edukasi tentang pentingnya pemenuhan kebutuhan personal hygiene lanjut usia, dan memotivasi lanjut usia dalam pemenuhan kebutuhan personal hygiene sesuai kemampuannya, serta membantu pemenuhan kebutuhan personal hygiene lanjut usia sesuai dengan tingkat ketergantungannya.

a. Tahap persiapan

Persiapan yang dilakukan meliputi pengurusan perijinan, survei lokasi, publikasi rencana pelaksanaan kegiatan, pendataan peserta, penyusunan jadwal, penyiapan sarana dan prasarana.

b. Tahap pelaksanaan

Kegiatan yang akan dilakukan dalam program pemenuhan kebutuhan personal hygiene lanjut usia ini meliputi:

1. Memberikan edukasi tentang pentingnya pemenuhan kebutuhan personal hygiene lanjut usia.

2. Memotivasi lanjut usia dalam pemenuhan kebutuhan personal hygiene sesuai kemampuannya.

3. Membantu pemenuhan kebutuhan personal hygiene lanjut usia sesuai dengan tingkat ketergantungannya.

1) Tingkat ketergantungan minimal: pengawasan, perawatan kuku, kebersihan lingkungan.

2) Tingkat ketergantungan sedang: perawatan kuku, perawatan mata, telinga, kebersihan lingkungan.

3) Tingkat ketergantungan total: perawatan kulit, perawatan kuku, perawatan gigi dan mulut, perawatan rambut, perawatan mata, perawatan telinga, perawatan hidung, dan perawatan perineum, kebersihan lingkungan.

\section{HASIL}

Unit Pelaksana Teknis (UPT) Pelayanan Sosial Lanjut Usia Jombang di Kediri berdiri sejak tahun 1948, merupakan peninggalan Belanda, dan dulunya dipergunakan sebagai rumah sakit untuk menampung para korban perang. Tahun 1950, oleh Belanda diserahkan kepada pihak Dinas Sosial Tingkat I Jawa Timur yang kemudian dipergunakan untuk menampung para lanjut usia yang pernah berjuang. Dinas Sosial Tingkat I Jawa Timur kemudian menyerahkan pengelolaan panti kepada Dinsos Sosial Kabupaten Kediri. Berdasarkan peraturan Gubernur Jawa Timur No. 119 tahun 2008, UPT Tresna Werdha Pare berubah menjadi UPT PSLU Jombang di Kediri

Unit Pelaksana Teknis (UPT) PSLU Jombang di Kediri merupakan panti werdha dengan induk adalah UPT PSLU Jombang yang beralamat di Jombang.. UPT PSLU Jombang di Kediri ini dibangun di tanah seluas $4.575 \mathrm{~m}^{2}$, dan luas bangunan $1.169,17 \mathrm{~m}^{2}$, serta memiliki kapasitas tampung sebanyak 85 orang. Data pada bulan November 2019 menunjukkan bahwa UPT PSLU Jombang di Kediri ini dihuni oleh 85 orang lanjut usia, yang sebagian besar adalah wanita dan berstatus janda, sedangkan untuk usia, lanjut usia penghuni UPT PSLU Jombang di Kediri berusia antara 60-100 tahun. UPT PSLU Jombang 
di Kediri mempunyai enam wisma tempat tinggal yang terdiri dari wisma mawar, anggrek, melati, dahlia, AWF A, dan AWF B, setiap wisma digolongkan berdasarkan jenis kelamin dan kapasitasnya

Data kepegawaian pada bulan November 2019 menunjukkan bahwa di UPT PSLU Jombang di Kediri mempunyai 20 orang pegawai dengan 2 orang perawat, selain itu PSLU juga melaksanakan banyak kegiatan antara lain :

1) Ibadah: setiap hari pihak panti melaksanakan sholat berjamaah di mushola panti dan doa bersama.

2) Olah raga: 2 kali dalam seminggu diadakan senam lanjut usia pada pagi hari.

3) Kesehatan dan beberapa bimbingan ketrampilan.

Persyaratan masuk UPT PSLU Jombang di Kediri adalah lanjut usia terlantar yang di utamakan tidak mempunyai keluarga, berusia minimal 60 tahun, tidak mempunyai kecacatan, tidak menderita penyakit kronis, dan mampu merawat/melayani dirinya sendiri dalam kegiatan sehari-hari. Jumlah lanjut usia yang masuk ke UPT PSLU Jombang di Kediri setiap bulannya tergantung dari kapasitas tempat tidur yang kosong. Kondisi lanjut usia yang mengalami penurunan baik fisik, psikis, sosial, maupun spiritual tersebut menyebabkan penurunan dalam pemenuhan kebutuhan personal hygiene.

\section{PEMBAHASAN}

Personal Hygiene berasal dari bahasa Yunani yaitu personal yang artinya perorangan dan hygiene berarti sehat. Menurut Simamora, (2011) perawatan diri adalah salah satu kemampuan dasar manusia dalam memenuhi kebutuhannya guna memepertahankan kehidupan, kesehatan dan kesejahteraan sesuai dengan kondisi kesehatannya. Lanjut usia dinyatakan terganggu keperawatan dirinya jika tidak dapat melakukan perawatan diri (Bago, 2018; Kustanti, Sudaryanto, Zulaicha, \& Kp, 2012). Defisit perawatan diri adalah gangguan kemampuan untuk melakukan aktivitas perawatan diri (mandi, berhias, makan, toileting) (Munawati, 2018). Menurut Poter, 2005 defisit perawatan diri adalah kondisi dimana seseorang tidak mampu melakukan perawatan kebersihan untuk dirinya (dalam Madalise, Bidjuni, \& Wowiling, 2015). Jika seorang lanjut usia sakit, biasanya masalah kebersihan kurang diperhatikan. Hal ini terjadi karena anggapan yang keliru menyepelekan masalah kebersihan, padahal jika hal tersebut dibiarkan terus dapat mempengaruhi kesehatan secara umum. Karena itu hendaknya setiap individu lanjut usia selalu berusaha supaya personal hygiennya dipelihara dan ditingkatkan. Kebersihan dan kerapian sangat penting dan diperlukan agar lanjut usia disenangi dan diterima dalam pergaulan, tetapi juga karena kebersihan diperlukan agar lanjut usia dapat hidup secara sehat.

Pendidikan kesehatan sangat berperan terhadap pemenuhan personal hygiene pada lanjut usia karena hal ini akan meningkatkan pengetahuan dan upaya untuk merubah perilaku seseorang. Hal ini didukung dalam (Anjarsari, Widodo, Kartinah, Hudiyawati, \& Kep, 2017; Tirtana \& Kirnantoro, 2011; Wardani, Widyastika, Ardiana, Sila, \& Asri, 2018) yang menunjukkan adanya pengaruh pemberian pendidikan kesehatan terhadap tingkat pengetahuan lanjut usia. Diperkuat dalam Saputri, Muhlisin, Budinugroho, \& Ns, (2015) yang menyatakan bahwa pemberian pendidikan kesehatan pada perokok sangat efektif dalam mengubah pengetahuan, sikap dan perilaku. Menurut penelitian yang dilakukan oleh (Muchtar, 2017; Yulizawati, Nurdiyan, Iryani, \& Insani, 2017) pendidikan kesehatan berpengaruh secara signifikan terhadap pengetahuan dan sikap perempuan yang menerima intervensi pendidikan kesehatan. Jadi pemberian pendidikan kesehatan dapat mempengaruhi terbentuknya perilaku pada seseorang. 
Pemberian pendidikan kesehatan tentang personal hygiene pada lanjut usia merupakan hal yang penting agar lanjut usia dapat lebih memperhatikan perilaku dalam melakukan personal hygiene demi kesehatan dan kenyamanan diri. Diharapkan lanjut usia dapat tetap memelihara kebersihan diri untuk meningkatkan derajat kesehatan, sehingga lanjut usia dapat menikmati masa tua yang sehat, bahagia dan berdaya guna. Kebersihan diri dapat mempengaruhi kenyamanan, keamanan, kesejahteraan lanjut usia, hal ini dapat meningkatkan kualitas hidup lanjut usia. Keberhasilan dari suatu pendidikan kesehatan dipengaruhi oleh strategi, metode dan alat bantu pengajaran. Dalam program ini menggunakan metode pendekatan dan diskusi/tanya jawab langsung secara personal. Kunci keberhasilan pelaksanaan pendekatan personal adalah apabila perawat dapat menguasai materi dan bisa memberi jawaban yang tepat atas pertanyaan lanjut usia sehingga seluruh lanjut usia dapat menyampaikan masalah dan memperoleh solusi yang diharapkan. Pernyataan ini diperkuat olehpernyataan (Dina, 2017; Nurlita, 2017; Widyaloka, 2017) yang melakukan pendidikan kesehatan yang disertai dengan penggunaan pendekatan personal dan hasilnya terdapat pengaruh secara signifikan terhadap pengetahuan dan sikap lanjut usia yang menerima intervensi pendidikan kesehatan. Dari uraian di atas dapat disimpulkan bahwa pemberian pendidikan kesehatan tentang personal hygiene pada lanjut usia dapat mempengaruhi perubahan perilaku kesehatan lanjut usia ke arah yang lebih baik dari sebelumnya.

\section{KESIMPULAN DAN SARAN}

Pelaksanaan pemenuhan kebutuhan personal hygiene pada lanjut usia di UPT Pelayanan Sosial Lanjut Usia Jombang di Pare menunjukkan bahwa sebanyak 50\% lanjut usia mengalami masalah pada pemenuhan kebutuhan personal hygiene. Kebutuhan personal hygiene terbanyak adalah pada berhias, memotong kuku, menyisir rambut, kebersihan tempat tidur, dan pakaian. Pemenuhan kebutuhan personal hygiene yang dilakukan di UPT Pelayanan Sosial Lanjut Usia Jombang di Pare dilakukan sesuai dengan tingkat ketergantungan dari lanjut usia yang ada, termasuk edukasi dan motivasi pada lanjut usia dalam pemenuhan kebutuhan personal hygiene. Lanjut usia mandiri akan dapat melakukan pemenuhan kebutuhan personal hygiene secara penuh, lanjut usia ketergantungan minimal akan dilakukan pengawasan atau pendampingan dalam pemenuhan kebutuhan personal hygiennya, lanjut usia dengan ketergantungan sebagian dan ketergantungan total akan membutuhkan bantuan perawat untuk memenuhi pemenuhan kebutuhan personal hygiennya, baik sebagian ataupun penuh. Jumlah perawat atau tenaga kesehatan yang minimal di UPT Pelayanan Sosial Lanjut Usia memerlukan perhatian yang khusus dari Pemerintah Daerah. Peran serta masyarakat, lembaga, maupun institusi pendidikan kesehatan sebagai pencetak generasi tenaga kesehatan masa depan harus dapat menjadi solusi terhadap pemenuhan kebutuhan kesehatan lanjut usia.

\section{REFERENSI}

Anjarsari, R. A., Widodo, A., Kartinah, S. K., Hudiyawati, D., \& Kep, M. (2017). Pengaruh Pendidikan Kesehatan Hipertensi Terhadap Pengetahuan Dan Persepsi Lanjut Usia Tentang Penyakit Hipertensi Di Desa Malangjiwan Kecamatan Colomadu. DISS, UNIVERSITAS MUHAMMADIYAH SURAKARTA.

Bago, A. (2018). HUBUNGAN PENGETAHUAN DAN SIKAP PEKERJA PABRIK KELAPA SAWIT DENGAN PERSONAL HYGIENE PERORANGAN DI PT. SIMPANG KANAN LESTARINDO DESA SIMPANG KANAN KABUPATEN 
ROKAN HILIR RIAU TAHUN 2018. DISS, Institut Kesehatan Helvetia.

Dina, R. (2017). PENGARUH PENDIDIKAN KESEHATAN TERHADAP KEPATUHAN MINUM OBAT HIPERTENSI PADA LANJUT USIA DI POSYANDU LANJUT USIA DESA LEBAK AYU KEC. SAWAHAN KABUPATEN MADIUN. DISS, STIKES Bhakti Husada Mulia.

Firmana, A. R. (2016). Gambaran Perilaku Hidup Bersih Dan Sehat (PHBS) Pada Lanjut usia Di Desa Kemukus Kecamatan Gombong Kabupaten Kebumen. DISS, STIKES MUHAMMADIYAH GOMBONG.

Husnia, R. (2007). Pengaruh Pendidikan Kesehatan terhadap Tingkat Pengetahuan dan Sikap Lanjut usia tentang Demensia di Panti Wredha Wening Wardoyo Ungaran. DISS, Diponegoro University.

Kustanti, N., Sudaryanto, A., Zulaicha, E., \& Kp, S. (2012). Kualitas hidup lanjut usia dengan hipertensi di wilayah kerja Puskesmas Karangmalang Kabupaten Sragen. DISS, Universitas Muhammadiyah Surakarta.

Lubis, N. L. (2016). Psikologi Kespro. Wanita dan Perkembangan Reproduksinya: Ditinjau dari Aspek Fisik dan Psikologinya. BOOK, Kencana.

Madalise, S., Bidjuni, H., \& Wowiling, F. (2015). Pengaruh Pemberian Pendidikan Kesehatan Pada Pasien Gangguan Jiwa (Defisit Perawatan Diri) Terhadap Pelaksanaan Adl (Activity Of Dayli Living) Kebersihan Gigi Dan Mulut Di Rsj Prof. Dr. V. L Ratumbuysang Ruang Katrili. JURNAL KEPERAWATAN, 3(2). JOUR.

Maryani, H., \& Kristiana, L. (2018). PEMODELAN ANGKA HARAPAN HIDUP (AHH) LAKI-LAKI DAN PEREMPUAN DI INDONESIA TAHUN 2016. Buletin Penelitian Sistem Kesehatan, 21(2), 71-81. JOUR.

Muchtar, H. M. (2017). Model Pendidikan Kesehatan Terhadap Pengetahuan dan Sikap Dalam Kesiapan Menghadapi Menarche Di Sekolah Dasar. Menara Ilmu, 11(75). JOUR.

Muhith, A., \& Siyoto, S. (2016). Pendidikan keperawatan gerontik. BOOK, Penerbit Andi. Munawati, E. (2018). Asuhan Keperawatan Gerontik dengan Masalah Gangguan Perawatan Diri pada Lanjut usia Demensia. DISS, Universitas Airlangga.

Nurfauziya, A., Prakosa, K. B., \& Kusuma, H. (2018). Dampak Desentralisasi Fiskal Terhadap Kesehatan Masyarakat (Studi Di Provinsi Daerah Istimewa Yogyakarta). Future: Jurnal Manajemen Dan Akuntansi, 5(2), 191-209. JOUR.

Nurlita, W. A. (2017). HUBUNGAN DUKUNGAN TENAGA KESEHATAN DENGAN PERILAKU PENCEGAHAN HIPERTENSI LANJUT USIA DI POSYANDU NURUS-ASYFA RW 01 KELURAHAN TLOGOMULYO SEMARANG. DISS, Universitas Muhammadiyah Semarang.

Rohmah, E. F. (2019). PENGALAMAN KELUARGA MERAWAT LANJUT USIA PASCA STROKE DALAM PEMENUHAN KEBUTUHAN HIDUP SEHARI-HARI DI WILAYAH PUSKESMAS DUKUN KABUPATEN GRESIK. DISS, Universitas Airlangga.

Saputri, Y. I., Muhlisin, H. M. A., Budinugroho, A., \& Ns, S. K. (2015). Pengaruh pendidikan kesehatan terhadap pengetahuan dan kepatuhan diit hipertensi pada lanjut usia di desa Wironanggan Kecamatan Gatak Sukoharjo. DISS, Universitas Muhammadiyah Surakarta.

Simamora, F. A. (2011). Hubungan Antara Tingkat Kemampuan Perawatan Diri Lanjut usia Dengan Perubahan Konsep Diri Lanjut usia Di Upt Pelayanan Sosial Lanjut Usia Dan Anak Balita Wilayah Binjai Dan Medan. JOUR.

Syaifudin, A., \& Nurhayati, S. (2018). Media Informasi Latihan Isotonik Membantu 
Meningkatkan Rentang Gerak Sendi Lutut pada Lanjut usia di Desa Leyangan Ungaran. Proceeding of The URECOL, 46-52. JOUR.

Tasti, L. (2018). HUBUNGAN KEMANDIRIAN LANJUT USIA (ELDERLY) DENGAN PERILAKU PERSONAL HYGIENE DI UPTD GRIYA WREDHA JAMBANGAN SURABAYA. DISS, Universitas Merdeka.

Tiar, A. C. (2019). MOTIVASI PERAWATAN DIRI LANJUT USIA Di UPT PSLU Kabupaten Magetan. DISS, Universitas Muhammadiyah Ponorogo.

Tirtana, A., \& Kirnantoro, K. (2011). Pengaruh Pendidikan Kesehatan Terhadap Pengetahuan Hipertensi Pada Lanjut usia Hipertensi Di Rw 04 Tegal Rejo Kelurahan Tegal Rejo Tahun 2011. DISS, STIKES'Aisyiyah Yogyakarta.

Usman, R. D. (2016). IDENTIFIKASI UPAYA PEMELIHARAAN PERSONAL HYGIENE PADA LANJUT USIA DI PANTI SOSIAL TRESNA WERDHA MINAULAKOTA KENDARI. DISS, Poltekkes Kemenkes Kendari.

Wardani, R., Widyastika, K. S., Ardiana, O. J., Sila, I. M., \& Asri, R. L. T. (2018). Pengaruh Pendidikan Kesehatan Hipertensi terhadap Pengetahuan Lanjut usia di Posyandu Lanjut usia Kelurahan Manisrenggo. Journal of Community Engagement in Health, 1(2), 25-28. JOUR.

Widyaloka, A. (2017). Hubungan Dukungan Keluarga Dengan Perilaku Pencegahan Hipertensi Lanjut usia Di Puskesmas Tlogosari Wetan Kota Semarang. DISS, Universitas Muhammadiyah Semarang.

Yulaikhah, D., Arisdiani, T., \& Widiastuti, Y. P. (2017). PERILAKU PERSONAL HYGIENE LANJUT USIA. Jurnal Keperawatan, 9(2), 44-51. JOUR.

Yulizawati, Y., Nurdiyan, A., Iryani, D., \& Insani, A. A. (2017). Pengaruh Pendidikan Kesehatan Metode Peer Education Mengenai Skrining Prakonsepsi Terhadap Pengetahuan Dan Sikap Wanita Usia Subur Di Wilayah Kabupaten Agam Tahun 2016. Journal of Midwifery, 1(2), 11-20. JOUR. 